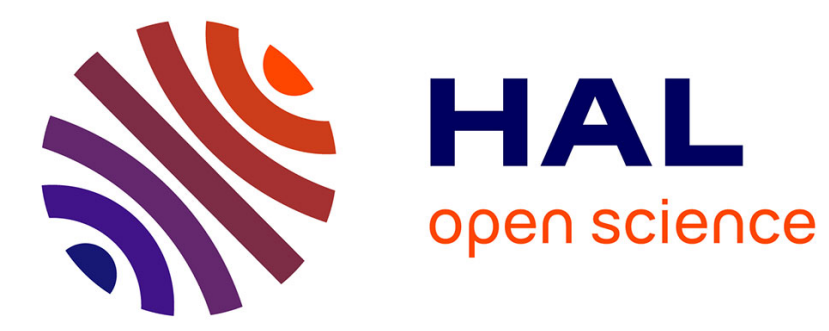

\title{
Formation of a trivalent chromium conversion coating on AZ91D magnesium alloy
}

\author{
Jiantao Qi, Zonghao Ye, Ning Gong, Xuelian Qu, Dimitri Mercier, Jolanta \\ Światowska, Peter Skeldon, Philippe Marcus
}

\section{- To cite this version:}

Jiantao Qi, Zonghao Ye, Ning Gong, Xuelian Qu, Dimitri Mercier, et al.. Formation of a trivalent chromium conversion coating on AZ91D magnesium alloy. Corrosion Science, 2021, 186, pp.109459. 10.1016/j.corsci.2021.109459 . hal-03433248

\section{HAL Id: hal-03433248 \\ https://hal.science/hal-03433248}

Submitted on 17 Nov 2021

HAL is a multi-disciplinary open access archive for the deposit and dissemination of scientific research documents, whether they are published or not. The documents may come from teaching and research institutions in France or abroad, or from public or private research centers.
L'archive ouverte pluridisciplinaire HAL, est destinée au dépôt et à la diffusion de documents scientifiques de niveau recherche, publiés ou non, émanant des établissements d'enseignement et de recherche français ou étrangers, des laboratoires publics ou privés. 


\title{
Formation of a trivalent chromium conversion coating on AZ91D magnesium alloy
}

\author{
Jiantao Qi ${ }^{a, *}$, Zonghao Ye ${ }^{a}$, Ning Gong ${ }^{a}$, Xuelian Qu ${ }^{a, b}$, Dimitri Mercier ${ }^{c}$, \\ Jolanta Światowska $^{\mathrm{c}, *}$, Peter Skeldon ${ }^{\mathrm{d}, *}$, Philippe Marcus ${ }^{c}$ \\ ${ }^{a}$ College of New Energy, China University of Petroleum (East China), Qingdao, 266580, PR China \\ ${ }^{\mathrm{b}}$ Qingdao Institute of Bioenergy and Bioprocess Technology, Chinese Academy of Science, 266101, PR China \\ ${ }^{c}$ PSL Research University, Chimie Paris Tech - CNRS, Institut De Recherche De Chimie Paris, Physical Chemistry of Surfaces Group, 11 Rue Pierre Et Marie Curie, \\ 75005, Paris, France \\ ${ }^{\mathrm{d}}$ Corrosion and Protection Centre, The University of Manchester, Oxford Rd., Manchester, M13 9PL, United Kingdom
}

\section{A B STRACT}

Trivalent chromium conversion (TCC) coating formation on AZ91D magnesium alloy has been investigated using scanning electron microscopy, energy X-ray dispersive spectroscopy (EDS), X-ray photoelectron spectroscoy (XPS). The coating was formed in a commercial SurTec 650 bath. XPS showed that coatings contained mainly $\mathrm{Cr}$,

$\mathrm{Zr}, \mathrm{O}, \mathrm{S}$ and $\mathrm{F}$ species, which were assigned to hydrated $\mathrm{Cr}(\mathrm{III})\left(\mathrm{Cr}(\mathrm{OH})_{3} / \mathrm{CrOOH}\right), \mathrm{ZrO}_{2}, \mathrm{Cr}_{2}\left(\mathrm{SO}_{4}\right)_{3}$, and $\mathrm{CrF}_{3}$, and

lower amounts of $\mathrm{Mg}^{2+}$ and $\mathrm{Al}^{3+}$ species assigned to oxide, hydroxide and fluoride. The $\mathrm{Cr} / \mathrm{Zr}$ atomic ratio was around 0.5 . The coating was formed above both $\alpha$ matrix and $\beta\left(\mathrm{Mg}_{17} \mathrm{Al}_{12}\right)$ grain boundary regions, and it was significantly thicker above the cathodic $\beta$ phase. Raman spectroscopy evidenced the presence of $\mathrm{Cr}(\mathrm{VI})$ species, formed due to oxidation of $\mathrm{Cr}(\mathrm{III})$ by $\mathrm{H}_{2} \mathrm{O}_{2}$, particularly in the coating above the cathodic sites. Electrochemical

impedance spectroscopy revealed that corrosion protection was provided mainly by the barrier layer at the base of the coating, which resulted in a reduction

keywords: Trivalent chromium Conversion coating Magnesium alloy Corrosion protection Surface pre-treatment

\section{Introduction}

Owing to their light weight, magnesium alloys are often considered as next-generation structural materials in transportation systems. However, the reactivity of magnesium (standard electrode potential $-2.37 \mathrm{~V}$ vs. SHE) and the presence of cathodic second phases lead to the high corrosion sensitivity in aqueous and atmospheric environments [1-3]. Chemical conversion treatment is often an economic and efficient surface treatment to provide corrosion protection. For instance, Hu et al. [4] treated AZ91D alloys in stannate solution, forming a $5 \mu \mathrm{m}$-thick coating that protected against corrosion in $3.5 \% \mathrm{NaCl}$ solution. Phosphate-based conversion coatings have also been employed that result in an insoluble deposit of $\mathrm{Mg}_{3}\left(\mathrm{PO}_{4}\right)_{2}$ [5]. Zai et al. compared different deposition parameters and revealed that a coating formed at 80 - $\mathrm{C}$ and at a $\mathrm{pH} 3$ offered the best corrosion resistance [6]. Chunyan etal. [7] proposed a phosphate-based conversion coating using the ratio of total acidity $(\mathrm{TA})$ relative to the $\mathrm{pH}$, with a low $\mathrm{TA} / \mathrm{pH}$ ratio generating a homogeneous coating microstructure with improved corrosion performance.

Chromate conversion coatings (CCCs) have been among the most successful surface treatments for light alloys, most particularly for aluminium alloys. [8,9] However their industrial application is now severely restricted as $\mathrm{Cr}(\mathrm{VI})$ is highly toxic, and classified as CMR (carcinogenic, mutagenic and reprotoxic) [10]. Trivalent chromium conversion (TCC) coatings with low toxicity and allowable environmental limits are regarded as promising alternative to CCCs [11]. TCC coatings are formed by a simple, brief dipping process, hence requiring no electrical facilities as are necessary for other common conversion treatments of magnesium alloys, such as anodizing or plasma electrolytic oxidation [12-14].

According to our knowledge one of the first studies on application of TCC coatings (SurTec 650) on AZ31B and ZE10A magnesium alloys was demonstrated by Brady et al. [15]. The coating composed of an inner $\mathrm{Mg}-\mathrm{F}-\mathrm{O}$ and an outer $\mathrm{Zr}$-Cr-O layer showed the improved corrosion resistance. Potentiodynamic polarization of the alloy in saturated $\mathrm{Mg}$ $(\mathrm{OH})_{2}$ solution containing $1 \mathrm{wt} \% \mathrm{NaCl}$ indicated minor, if any,

\footnotetext{
${ }^{*}$ Corresponding authors.

E-mail addresses: jiantao.qi@upc.edu.cn (J. Qi), jolanta.swiatowska@chimieparistech.psl.eu (J. Światowska), peter.skeldon@manchester.ac.uk (P. Skeldon).
} 
Table 1

Composition of AZ91D alloy by ICP-OES (wt\%).

\begin{tabular}{llllllll}
\hline Element & $\mathrm{Al}$ & $\mathrm{Cu}$ & $\mathrm{Fe}$ & $\mathrm{Mn}$ & $\mathrm{Ni}$ & $\mathrm{Si}$ & $\mathrm{Zn}$ \\
\hline & 9.12 & $<0.01$ & $<0.004$ & 0.18 & $<0.001$ & 0.01 & 0.68 le \\
\hline
\end{tabular}

protection of the alloys.

The present work examines TCC coating formation (using a SurTec 650 bath) on AZ91D magnesium alloy. Attention is given to the role of the alloy microstructure in the development of the coating, which was
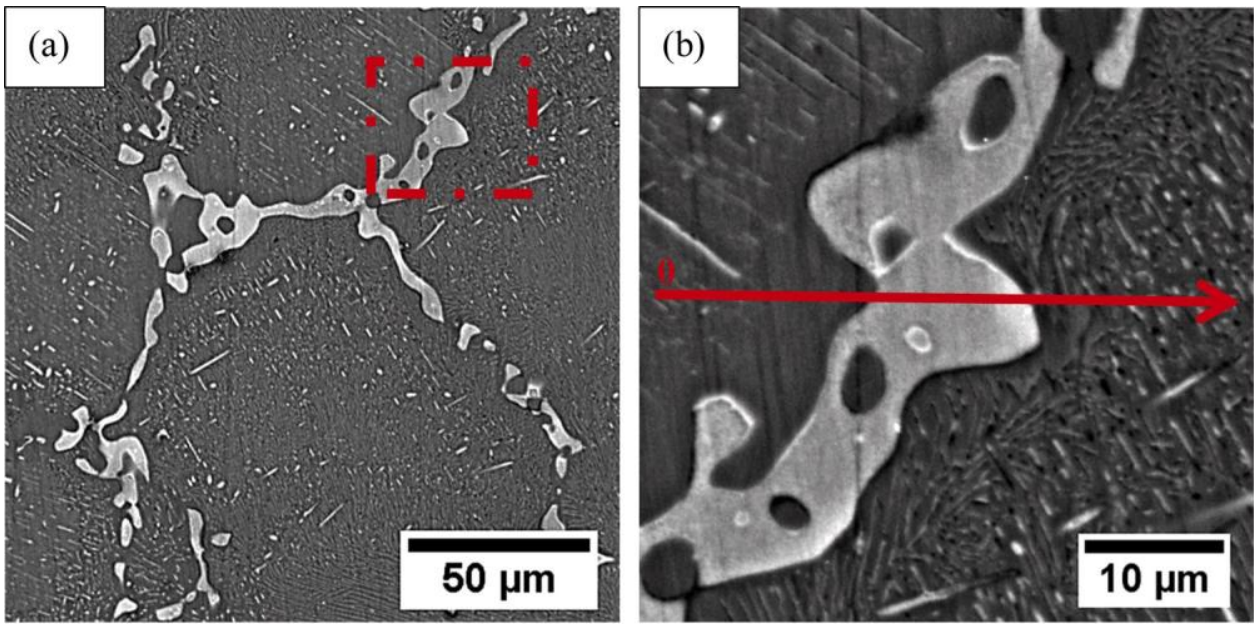

(c)
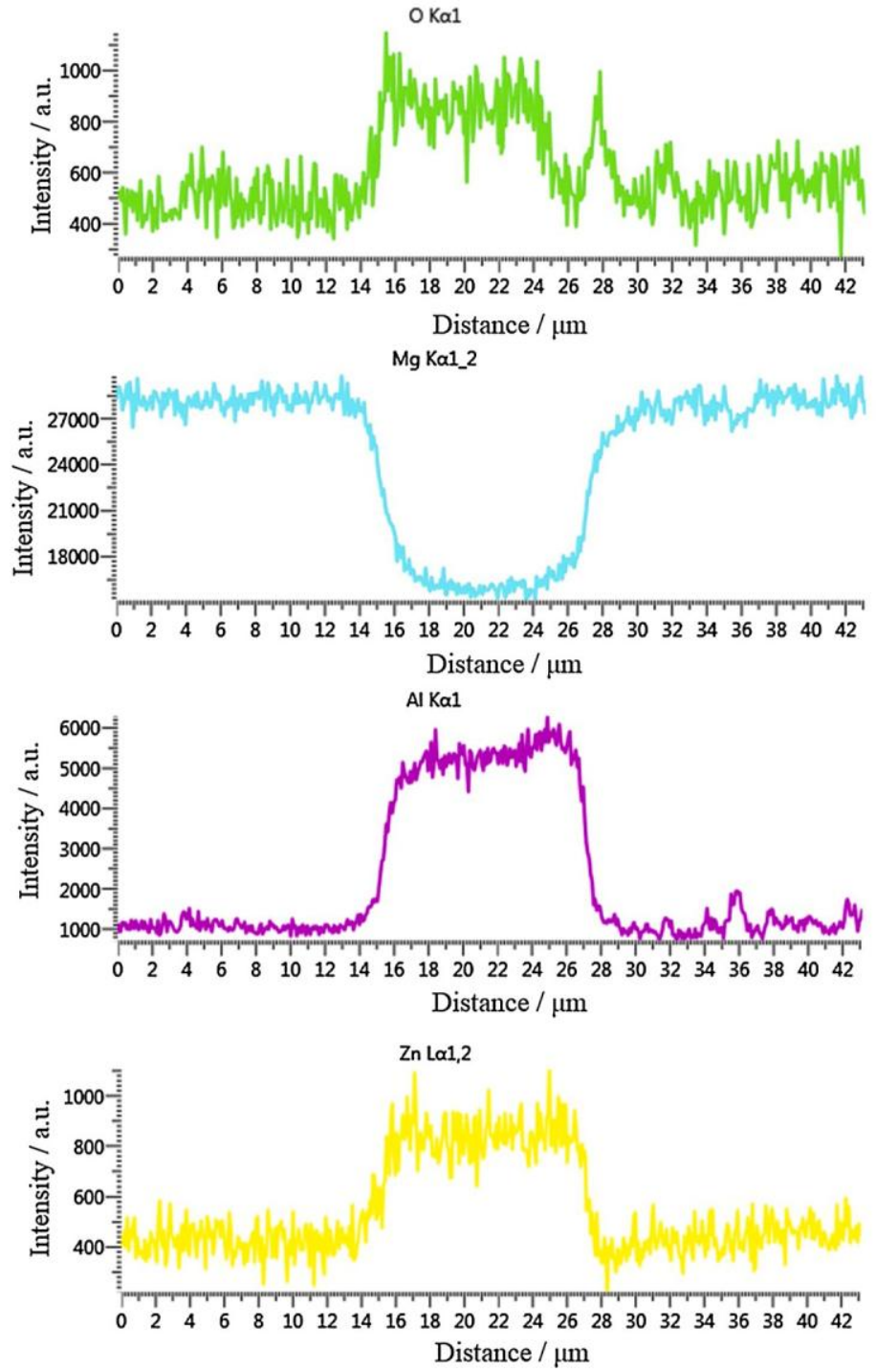

Fig. 1. (a, b) Scanning electron micrographs and (c) EDS line profiles analysis for O, Al, Mg and Zn in the pretreated bare AZ91D all oy. 
not considered in the earlier investigation. The study identifies the role of the cathodic $\beta$ phase $\left(\mathrm{Mg}_{17} \mathrm{Al}_{12}\right)$ and show preferential sites for the coating deposition. The coating morphology, chemical composition and corrosion protection performance were investigated by scanning electron microscopy, X-ray photoelectron spectroscopy, Raman spectroscopy and electrochemical measurements, respectively.

\section{Materials and methods}

\subsection{Specimen preparation}

Cast AZ91D alloy (Dongguan Magnesium Alloy Material Ltd, China) was cut to provide specimens of dimensions of $1515 \times 5 \mathrm{~mm}$. Table 1 displays the chemical analysis of the alloy performed by ICP-OES (Optima $4300 \mathrm{DV}$ ). The main alloying elements of the alloy are $\mathrm{Al}$ and $\mathrm{Zn}$ with 9.12 and 0.68 wt.\%, respectively.

The specimens were ground to a 2000 grit $\mathrm{SiC}$ finish, then polished with $1.0 \mu \mathrm{m}$ diamond paste, etched in $10 \mathrm{~g} / \mathrm{L} \mathrm{NaOH}+5 \mathrm{~g} / \mathrm{L} \mathrm{Na} \mathrm{CO}_{3}$ at $60{ }^{\circ} \mathrm{C}$ for $10 \mathrm{~min}$, deoxidized in $12.5 \mathrm{~g} / \mathrm{L} \mathrm{NH}_{4} \mathrm{HF}_{2}+3.5 \mathrm{~g} / \mathrm{L}$ glycolic acid $\left(\mathrm{C}_{2} \mathrm{H}_{2} \mathrm{O}_{3} \mathrm{H}_{2} \mathrm{O}\right)$ at $25{ }^{\circ} \mathrm{C}$ for $10 \mathrm{~s}$ and activated in $20 \% \mathrm{NaOH}$ at $25^{\circ} \mathrm{C}$ for $30 \mathrm{~min}$. All chemicals used for the pre-treatment were of analytical grade. Selected specimens were then TCC-coated using SurTec 650 (SurTec International Gmbh, Bensheim, Germany) solution as a bath for 10 min at $40^{\circ} \mathrm{C}$. The main constituents of SurTec 650 are chromium (III) and fluoro-zirconate salts. A previous ICP-OES of the solution by some of the present authors indicated a $\mathrm{Zr} / \mathrm{Cr}$ atomic ratio o 0.7 . [16]

All specimens were finally rinsed with deionized water and dried in a cool $\mathrm{N}_{2}$ stream. The coated specimens were stored for $15 \mathrm{~h}$ in laboratory air before examination. At least three specimens for each condition were prepared to ensure reproducibility. The deionized water used for solution preparation and rinsing was of resistivity $<18 \Omega \mathrm{cm}$.

\subsection{Electrochemical analysis}

A three-electrode cell, containing a AZ91 D working electrode (area $1 \mathrm{~cm}^{2}$ ), a platinum wire counter electrode (>99.99\%) and a saturated $\mathrm{Ag} / \mathrm{AgCl}$ reference electrode $(0.222 \mathrm{~V}$ vs $\mathrm{SHE})$, with an electrochemical workstation (CS310 (Wuhan, China)), was used for electrochemical measurements. Potentiodynamic polarization scans and electrochemical impedance spectroscopy (EIS) measurements were started after $30 \mathrm{~min}$ immersion at the open circuit potential (OCP) in $0.05 \mathrm{M} \mathrm{Na}_{2} \mathrm{SO}_{4}$ solution at room temperature. EIS measurements were made from $10^{5}$ to $10^{-2} \mathrm{~Hz}$ using a sinusoidal waveform of amplitude $10 \mathrm{mV}$. Anodic and cathodic polarization curves were recorded individually, starting from the OCP, at a scan rate of $1 \mathrm{mV} / \mathrm{s}$. Electrochemical measurements were repeated at least three times to check the reproducibility.

\subsection{Morphological and surface characterization}

Surface morphologies and compositions before and after coating deposition were investigated by scanning electron microscopy (SEM, JSM-7200 F and Helios 5 UX) and X-ray energy dispersive spectrometry (EDS) at an accelerating voltage of $15 \mathrm{kV}$. For measurement of the coating thickness, two specimens TCC-coated for $10 \mathrm{~min}$ and then spray coated with carbon were glued together and mechanically polished to a $1 \mu \mathrm{m}$ diamond finish in absolute alcohol solution. SEM/EDS was carried at $15 \mathrm{kV}$ using a JSM-7200 $\mathrm{F}$ instrument. X-ray photoelectron spectroscopy (XPS) was performed using a Thermo ESCALAB 250XI spectrometer, with monochromatic $\mathrm{Al} \mathrm{Ka}$ radiation $(\mathrm{hu}=1486.6 \mathrm{eV}$ ), operated at a base pressure of $\approx 10^{-10} \mathrm{mbar}$ and with energy step size of $0.05 \mathrm{eV}$. Survey spectra and high-resolution spectra (C 1s, O 1s, Mg 1s, Al 2p, Cr 2p, Zr 3d, F s1 and S 2p) were recorded with a pass energy of $100 \mathrm{eV}$ and $20 \mathrm{eV}$, respectively. Analyses were performed over a surface area of size $100 \times 100 \mu \mathrm{m}$, with a take-off angle of $90^{\circ}$. Charge correction was performed with reference to the hydrocarbon peak at $285.0 \mathrm{eV}$. All data processing was carried out with the AvantageTM software (Thermo Electron Corp.) using a Shirley type background and a

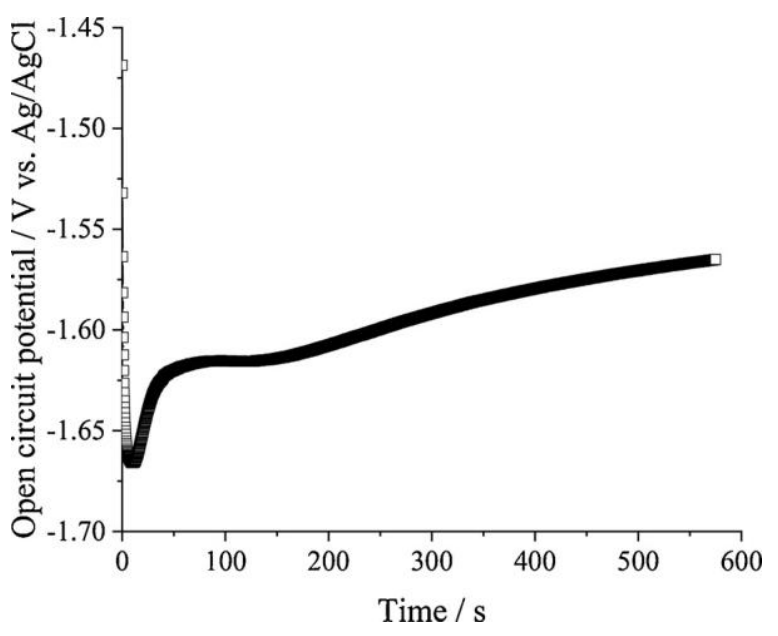

Fig. 2. Open-circuit potential-time curve for the AZ91D alloy immersed for 575 $\mathrm{s}$ in SurTec 650 solution at $40{ }^{\circ} \mathrm{C}$.

$70 \%$ Gaussian $30 \%$ Lorentzian line shape. In addition, Raman spectroscopy (Horiba LabRAM HR Evolution) was used to investigate the coating components using a $532 \mathrm{~nm}$ laser source, $10 \%$ power, 100x objective lens, exposure time of $10 \mathrm{~s}$ and no accumulation.

\section{Results and discussion}

\subsection{Alloy microstructure}

Fig. 1 (a) displays a low magnification scanning electron micrograph of the as-pre-treated surface revealing a grain boundary phase and platelike precipitates within the matrix. EDS analyses for $\mathrm{Al}$ and $\mathrm{Mg}$ in the boxed region of Fig. 1 (a), (shown enlarged in Fig. 1 (b)), revealed enrichment of aluminium in the grain boundary phase relative to the matrix (Fig. 1 (c)). The microstructure is consistent with grain boundary $\beta$ phase $\left(\mathrm{Mg}_{17} \mathrm{Al}_{12}\right)$ and plate-like $\beta$ precipitates in the matrix similarly to previous work [1]. This $\beta$ phase can be an effective cathode during corrosion of AZ91 alloy like demonstrated by Song et al. [16]. The EDS also shows the zinc enrichment at the grain boundaries $\beta$ phase, and oxygen originating from the surface oxide/hydroxide layer (Fig. 1 (c)).

\subsection{Coating formation and morphologies}

Fig. 2 shows the OCP-time curve for the AZ91D alloy during TCC coating formation in SurTec solution at $40{ }^{\circ} \mathrm{C}$ for $575 \mathrm{~s}$. Starting from an initial value of $\approx 1.50 \mathrm{~V}$, the potential decrease by $\approx 150 \mathrm{mV}$ in the first $10 \mathrm{~s}$ then gradual increase to $\approx 1.62 \mathrm{~V}$ by about $50 \mathrm{~s}$ can be observed. Thereafter, the increase is much slower, with a final potential of $\approx-1.57$ V. Oxidation of magnesium and hydrogen evolution are the main electrochemical reactions. The initial variations in potential such as decrease and increase are probably due to the oxidation of the alloy (principally the attack and dissolution of the surface oxide/hydroxide layer) and the coating formation, respectively. The coating formation is promoted at cathodic $\beta$ phase (shown later) and its consequential influence on the anodic and cathodic processes. The OCP evolution during TCC coating formation on magnesium alloys was similar to with that reported for aluminium and aluminium alloy. [17-19] TCC coating formation is a pH-driven process where the $\mathrm{pH}$ is locally increased by the cathodic reactions leading to enhanced deposition of hydroxides of chromium and zirconium. [20]

Fig. 3 (a) displays a scanning electron micrograph of a TCC-coated specimen at low magnification. The alloy surface has been covered by the TCC coating. The coating above the grain boundary $\beta$ phase exhibits a network of wide cracks, which are not present in the coating above the $\alpha$ matrix. A region of grain boundary $\beta$ phase is shown at higher 
(a)

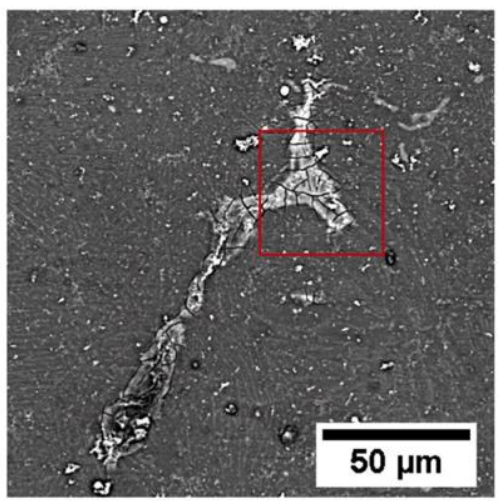

(b)

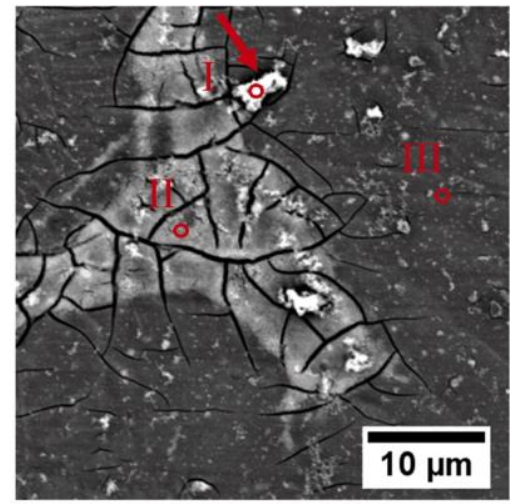

(c)

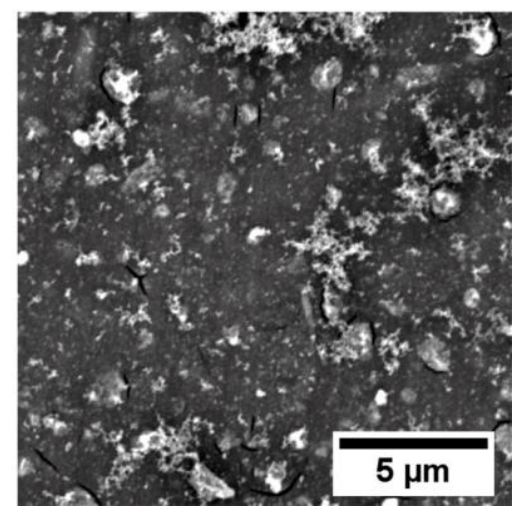

Fig. 3. Scanning electron micrographs of TCC-coated AZ91D alloy at (a) low and (b) high magnification and (c) TCC-coated $\alpha$ matrix.

magnification in Fig. 3 (b), and reveals the cracks propagation into the adjacent $\alpha$ matrix. Both the matrix and grain boundary $\beta$ phase are decorated by irregularly-shaped particles, of light appearance in the micrographs (see arrows), at both the $\alpha$ matrix and grain boundary $\beta$ phase (Fig. $3(a, b)$ ), with sizes from lower than $1 \mu \mathrm{m}$ to around $10 \mu \mathrm{m}$.

Fig. 3 (c) shows details of the coating surface at the $\alpha$ matrix. The coating is decorated by fine irregular in shaper particles (as already mentioned above) and reveals short length (a few microns) fine cracks, which contrast with the continuous network of coarse cracks in the coating above the grain boundary $\beta$ phase. The cracking may be due to the stress generated by shrinkage of the coating during drying in either the laboratory air or in the electron microscope.

To have a better insight into the differences in the coating composition over an irregular-shaped deposit (spot I), the grain boundary $\beta$ phase (spot II) and the $\alpha$ matrix (spot III), the EDS analyses were performed as shown in Fig. 3 (b). The $\mathrm{Cr} / \mathrm{Zr}$ atomic ratios at the respective areas were $\sim 0.68,0.52$ and 0.52 . The $\mathrm{Cr} / \mathrm{Zr}$ ratios for the coating at the matrix and $\beta$ phase grain boundary are similar to those found in TCC coatings formed on aluminium and AA 2024 alloy in a similar bath [19, (a)

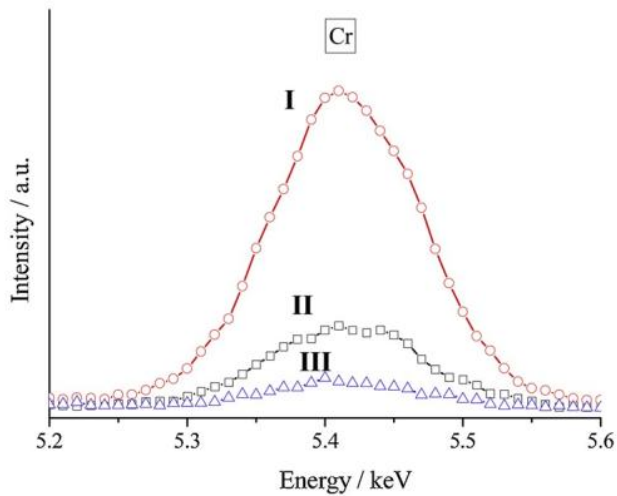

(b)

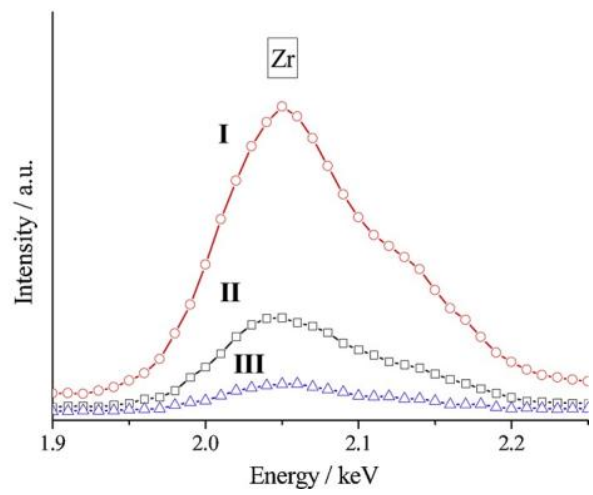

Fig. 4. EDS peaks for zirconium and chromium at spots I, II and III corresponding to over an irregular-shaped deposit, the grain boundary $\beta$ phase and the $\alpha$ matrix, respectively, shown in Fig. 3b.

21]. Fig. $4(a, b)$ shows the intensities of the chromium and zirconium peaks at these different areas I, II and III. The intensities of both peaks decreased in order I $>$ II $>$ III. The highest signals at region I are due to the large size and thickness of the irregularly-shaped particle relativeto the comparatively thin TCC coating layers on the grain boundary $\beta$ phase than at the $\alpha$ matrix. The chromium and zirconium peaks are about 3 times higher at the $\beta$ phase site compared with the $\alpha$ matrix region, which is consistent with a greater coating thickness at the former region.

The coating was examined in cross-section using backscattered electrons (Fig. 5). The coating above the alloy matrix (Fig. 5 (a)) revealed an outer layer of light appearance, with a thickness of $50 \mathrm{~nm}$, and an inner, darker layer of thickness $\approx 40 \mathrm{~nm}$. The thickness of the inner layer in particular was locally variable by up to a factor of 2 . The pore like-features of the inner layer are possibly the result of irradiation damage or dehydration by the electron beam. The outer layer contained chromium and zirconium, giving rise to enhance electron scattering compared with the inner, magnesium-rich layer. The coating above a region of $\beta$ phase was similarly two-layered (Fig. 5 (b)), with a thicker outer layer than above the matrix, $\approx 75 \mathrm{~nm}$. The thickness of the inner layer above the $\beta$ phase was similar to that above the matrix. The difference between the coating thickness on the $\alpha$ matrix and $\beta$ phase in the cross-sections is less significant than was deduced from the EDS analysis,

which may be related to a variable thicknesses over different $\beta$ phase regions. The higher thickness of the coating over the grain boundary $\beta$ phase may be explained by the cathodic activity (oxygen reduction and hydrogen evolution) and large area of the $\beta$ phase. The cathodic reactions result in a pH increase in the solution adjacent to the specimen surface. The interfacial $\mathrm{pH}$ can also be increased due to the solubility of $\mathrm{Mg}(\mathrm{OH})_{2}$ formed by the oxidation of the alloy. The principle 

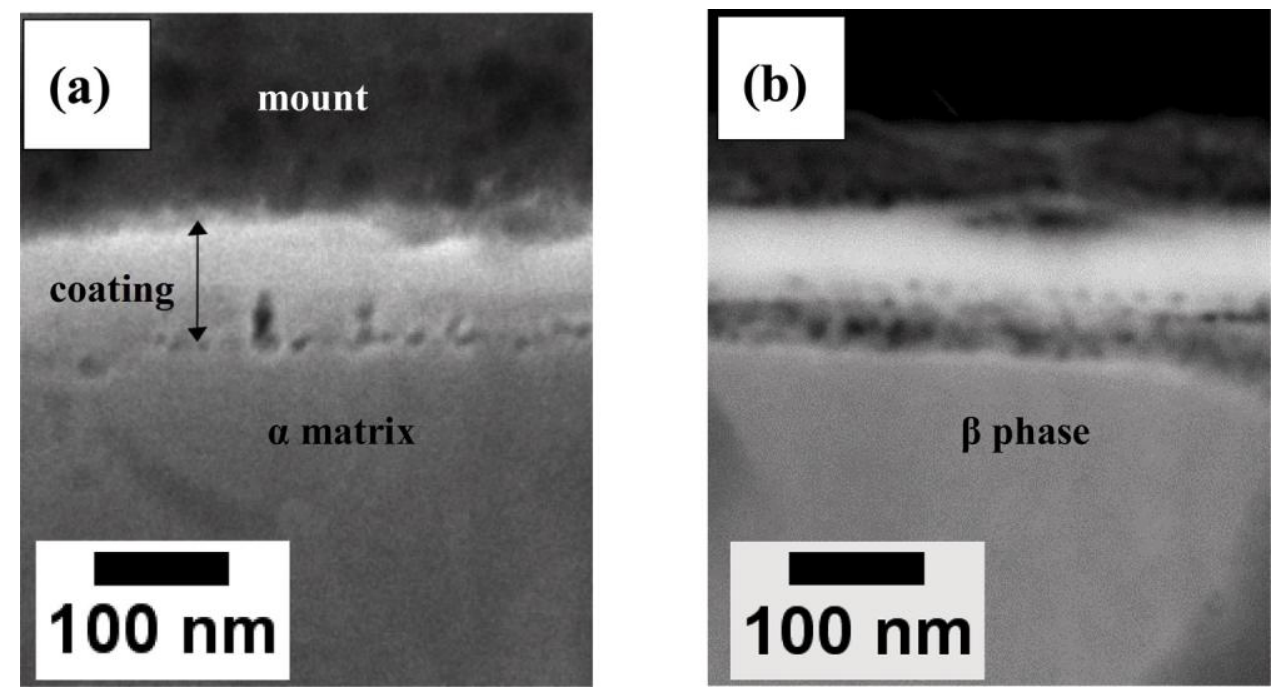

Fig. 5. Backscattered electron scanning electron micrographs of a cross-section of the TCC-coated AZ91D alloy. (a) $\alpha$ matrix and (b) $\beta$ phase.

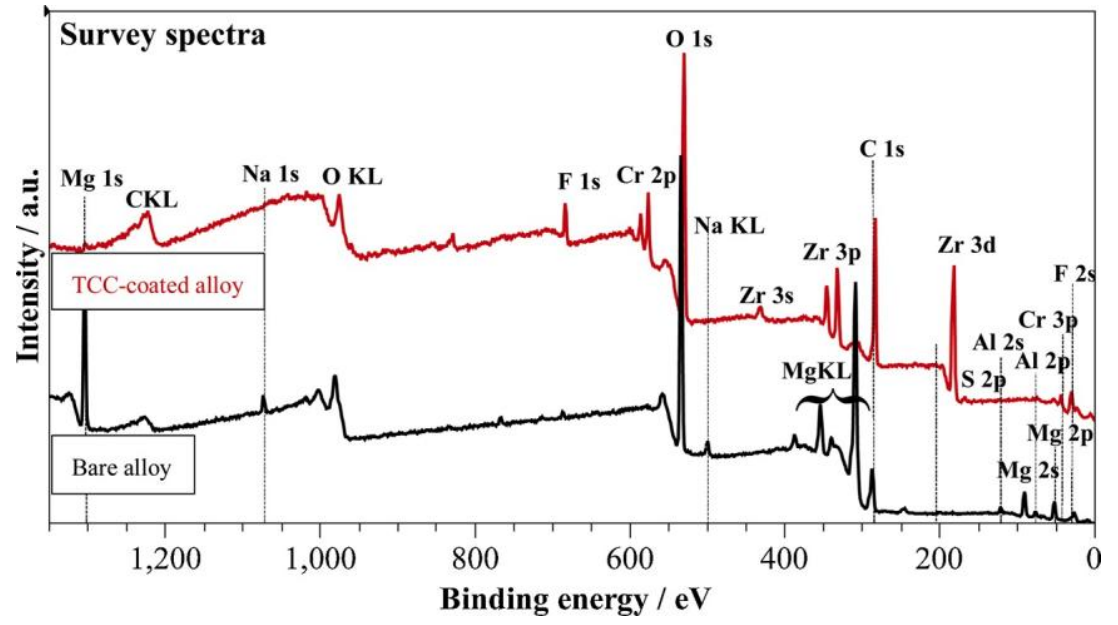

Fig. 6. XPS survey spectra for pretreated (bare) and TCC-coated AZ91D alloy.

components of the deposited coating material (shown later by XPS) consist of $\mathrm{ZrO}_{2}$ and hydrated $\mathrm{Cr}(\mathrm{III})$ species $\left(\mathrm{Cr}(\mathrm{OH})_{3} / \mathrm{CrOOH}\right)$ species, which are formed by the reactions:

$\mathrm{ZrF}_{6}^{2-}+4 \mathrm{OH}-\rightarrow \mathrm{ZrO}_{2}+6 \mathrm{~F}-+2 \mathrm{H}_{2} \mathrm{O}$

$\mathrm{Cr}^{3+}+3 \mathrm{OH}^{-} \rightarrow \mathrm{Cr}(\mathrm{OH})_{3}$

The greater in crease in $\mathrm{pH}$ at the grain boundary $\beta$ phase may be explained by the increased deposition of coating components relative to that at the $\alpha$ matrix. Beneath the deposited layer a thinner Mg-F-O layer can be formed due to the anodic oxidation of magnesium as shown by Brady et al. [12].

\subsection{Chemical characterization by XPS and raman spectroscopy}

Chemical surface characterization of specimens with and without TCC coating was performed by XPS (Fig. 6). Owing to the size of the analyzed area of the specimen surfaces $\left(500 \mu \mathrm{m}^{2}\right)$, the XPS analyses provide compositions averaged over regions of both $\alpha$ and $\beta$ phases to $a$ depth of $5-10 \mathrm{~nm}$. Fig. 6 compares the survey spectra of the two specimens pretreated (bare) and TCC-coated AZ91D alloy. Carbon, which was detected on both the bare and coated alloy, could originate from chemicals used in the pre-treatment and coating processes and from adsorption of organic species in the laboratory atmosphere. A detailed decomposition of the $\mathrm{C}$ 1s core level region for both specimens is presented in Fig. $7 \mathrm{a}$ and d. As shown in Fig. 7a, four peaks were distinguished: $\mathrm{C}-\mathrm{C}$ at $285.0 \mathrm{eV}(\mathrm{FWHM}=2.0 \mathrm{eV}), \mathrm{C}-\mathrm{O}$ at 286.6 (FWHM $=1.9 \mathrm{eV}), \mathrm{O}-\mathrm{C}=\mathrm{O}$ at $288.6 \mathrm{eV}(\mathrm{FWHM}=1.9 \mathrm{eV})$ and $-\mathrm{CO}_{3}$ at $290.8 \mathrm{eV}$ $(\mathrm{FWHM}=1.9 \mathrm{eV})$. After TCC treatment $(\mathrm{Fig} .7 \mathrm{~d})$, the carbon peak showed only three contributions: $\mathrm{C}-\mathrm{C}, \mathrm{C}-\mathrm{O}$ and $\mathrm{O}-\mathrm{C}=\mathrm{O}$. and the carbonate species $\left(-\mathrm{CO}_{3}\right)$ were not observed.

The alloy substrate before TCC treatment (bare alloy in Fig. 6) showed principally the presence of aluminium and magnesium oxyhydroxides due to the surface pre-treatment. The presence of aluminium and magnesium oxides and/or hydroxides was confirmed by the in-depth characterization of the high resolution $\mathrm{Al} 2 \mathrm{p}$ and $\mathrm{Mg} 1 \mathrm{~s}$ spectra, respectively (present in Fig. $7 \mathrm{~b}$ and c). The Al $2 p$ core level region shows one peak at $75.6 \mathrm{eV}(\mathrm{FWHM}=2.8 \mathrm{eV})$ corresponding to aluminium oxide or hydroxide $\left(\mathrm{Al}^{3+}\right)[18,22,23]$ and the $\mathrm{Mg} 1 \mathrm{~s}$ a peak at $1304.3 \mathrm{eV}(\mathrm{FWHM}=3.5 \mathrm{eV})$, which can be attributed to magnesium oxide/hydroxide $\left(\mathrm{Mg}^{2+}\right)[24,25]$. The large quantity of $\mathrm{MgO} / \mathrm{Mg}(\mathrm{OH})_{2}$ species can be revealed by the high intensity of the $\mathrm{Mg} 1 \mathrm{~s}$ peak, the other core levels peaks such as $\mathrm{Mg} 2 \mathrm{p}$ (at around $49 \mathrm{eV}$ ) and $\mathrm{Mg} 2 \mathrm{~s}$ (at around $86 \mathrm{eV}$ ) as well as series of $\mathrm{Mg}$ Auger peaks between $300-390 \mathrm{eV}$. After the formation of the TCC conversion layer (Fig. 6), the Al 2p and $\mathrm{Mg} 1 \mathrm{~s}$ peaks are significantly attenuated (as also showed by the surface composition presented in Table 2) indicating the formation of the 
a) Uncoated alloy

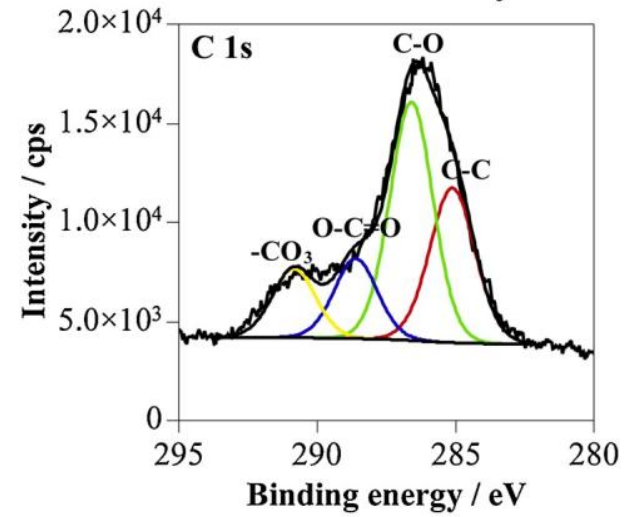

b) Uncoated alloy

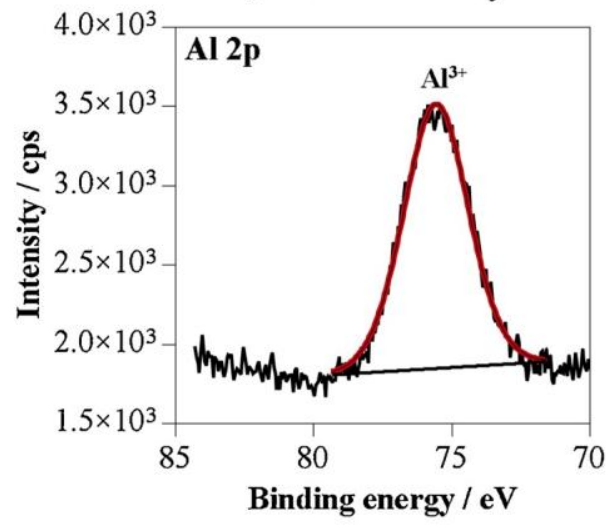

c) Uncoated alloy

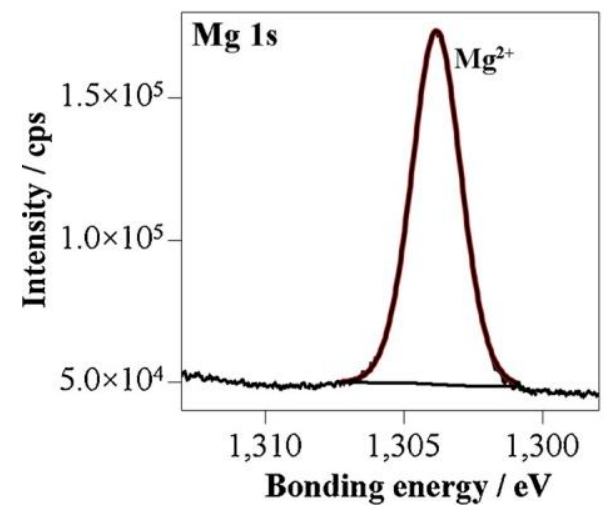

d) TCC-coated alloy

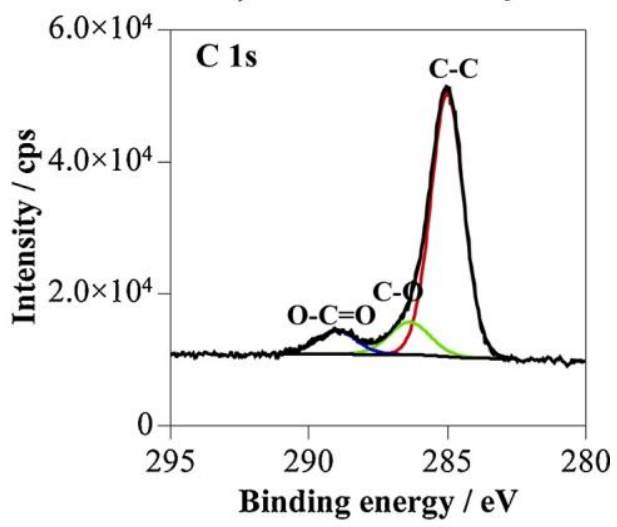

e) TCC-coated alloy

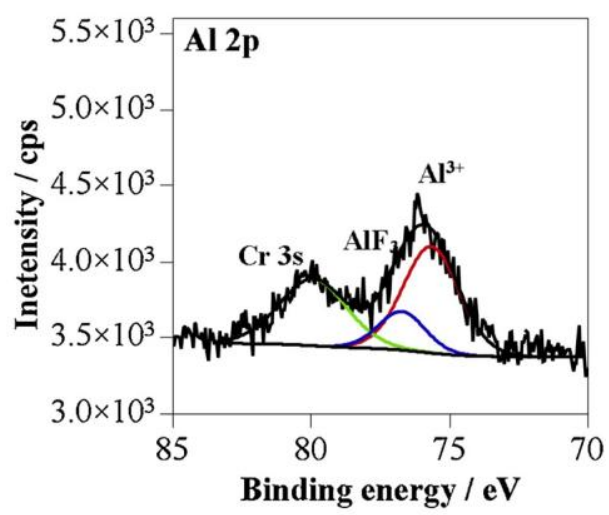

f) TCC-coated alloy

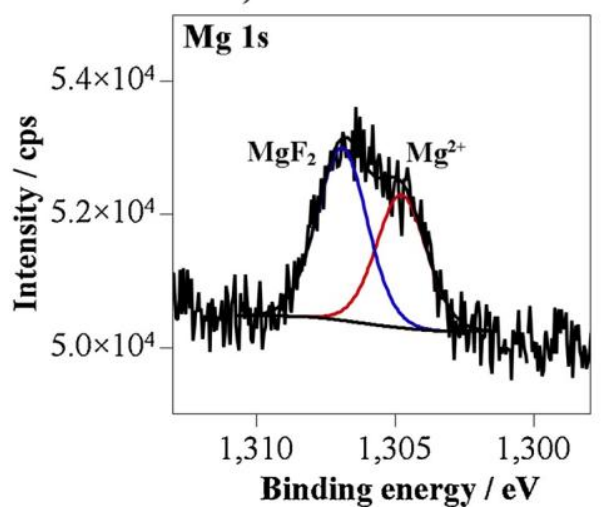

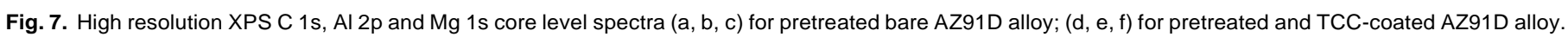

Table 2

Elemental concentrations (at.\%) for pretreated bare and TCC-coated AZ91D alloy from XPS. The coating was formed in SurTec 650 solution at $40{ }^{\circ} \mathrm{C}$ for 600 s.

\begin{tabular}{llllllll}
\hline Element & $\mathrm{Al}$ & $\mathrm{S}$ & $\mathrm{Zr}$ & $\mathrm{O}$ & $\mathrm{Cr}$ & $\mathrm{F}$ & $\mathrm{Mg}$ \\
\hline Bare alloy & 5.0 & $/$ & $/$ & 70.2 & $/$ & $/$ & 24.8 \\
TCC-coated alloy & 4.2 & 1.2 & 12.7 & 67.1 & 6.3 & 7.0 & 2.6 \\
\hline
\end{tabular}

conversion layer.

The high resolution $\mathrm{Al} 2 \mathrm{p}$ and $\mathrm{Mg} 1 \mathrm{~s}$ spectra for the TCC converted sample are presented in Fig. 7e and f, respectively. The lowest binding energy peaks corresponding to aluminium $\left(\mathrm{Al}^{3+}\right)$ and magnesium $\left(\mathrm{Mg}^{2+}\right)$ oxy-hydroxides are still present but they show much lower intensities than on the bare alloy (Fig. 6b and c). New components appeared in the $\mathrm{Al} 2 \mathrm{p}$ peak at $76.7 \mathrm{eV}(\mathrm{FWHM}=2.1 \mathrm{eV})$ and $80.0 \mathrm{eV}$ $(\mathrm{FWHM}=2.9 \mathrm{eV})$ corresponding to $\mathrm{AlF}_{3}[18,26]$ and $\mathrm{Cr} 3 \mathrm{~s}$, respectively. Formation of $\mathrm{AlF}_{3}$ can originate from the surface pretreatment or the conversion treatment bath. Low amounts of fluorine, and also sodium, 
a) TCC-coated alloy

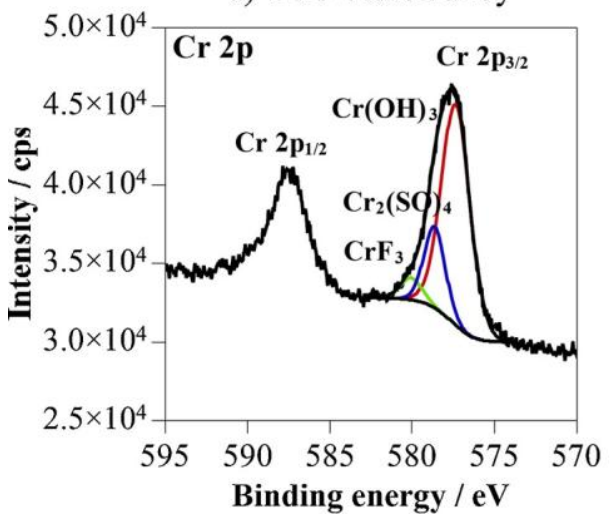

b) TCC-coated alloy

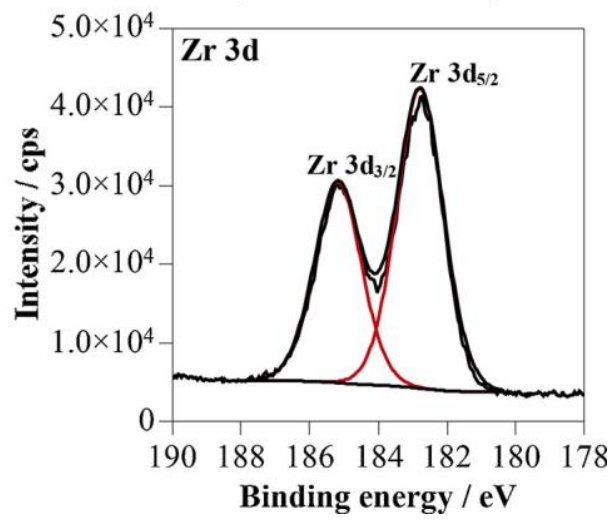

Fig. 8. High resolution XPS Cr 2p and Zr 3d core level spectra for TCC-coated AZ91D alloy.

Table 3

Components (\%) of TCC coating formed on AZ91D alloy in SurTec 650 solution at $40{ }^{\circ} \mathrm{C}$ for $600 \mathrm{~s}$, from XPS (using $\mathrm{Cr} / \mathrm{Zr}$ at. ratio in Table 2).

\begin{tabular}{lllll}
\hline Compound & $\mathrm{Cr}(\mathrm{OH})_{3}$ & $\mathrm{Cr}_{2}\left(\mathrm{SO}_{4}\right)_{3}$ & $\mathrm{CrF}_{3}$ & $\mathrm{ZrO}_{2}$ \\
\hline 24 & 2 & 6 & 68 \\
\hline
\end{tabular}

were observed on the uncoated alloy (Fig. 6). The presence of $\mathrm{AlF}_{3}$ has been observed on TCC-coated AA2024 alloy [18]. The appearance of $\mathrm{Cr}$ $3 s$ in the region of $\mathrm{Al} 2 \mathrm{p}$ core level peak corroborates with the presence of a coating containing $\mathrm{Cr}$ and $\mathrm{Zr}$ species, as discussed below.

A major difference observed in the survey spectra for the TCC treated specimen with reference to the non-converted is the appearance of peaks corresponding to zirconium ( $\mathrm{Zr} 3 \mathrm{~d}$ and other core level peaks $\mathrm{Zr}$ 3pand $\mathrm{Zr} 3 \mathrm{~s}$ ) and chromium (Cr 2p, and also Cr 3p) (Fig. 6). The Cr/Zratomic ratio is $\sim 0.49$ (Table 2). A decomposition of two principal $\mathrm{Cr}(\mathrm{Cr} 2 \mathrm{p})$ and $\mathrm{Zr}(\mathrm{Zr} \mathrm{3d})$ peaks is presented in Fig. 8. Other coating components are fluoride and sulfur, as evidenced by presence of $F 1 \mathrm{~s}$ and $S 2 p$ peaks, respectively. The surface elemental compositions for both samples are present in Table 3. The high at\% of $\mathrm{O} 1 \mathrm{~s}$ (Table 2 ) can be related not only to the presence of $\mathrm{Cr}$ and $\mathrm{Zr}$ oxides and hydroxides but also to the presence of oxygenated carbon-like contamination detected on both specimens as explained in the decomposition of the C1 s peak. The quantitative analysis of the surface composition was performed based on the high resolution spectra assuming a uniform and homogeneous surface layer for both the as-pretreated alloy and for the alloy after formation of the TCC conversion layer. The carbon-containing contamination was not taken into account for this analysis. The small amount of sodium and fluoride contamination on the surface of bare alloy was also neglected in the quantitative analysis of the surface composition.

Fig. 8 presents high resolution $\mathrm{Cr} 2 \mathrm{p}$ (a) and Zr 3d (b) spectra obtained for the TCC converted sample. The $\mathrm{Cr} 2 \mathrm{p}$ spectrum shows a spin orbit doublet with two well-separated peaks, $\mathrm{Cr} 2 \mathrm{p}_{3 / 2}$ and $\mathrm{Cr} 2 \mathrm{p}_{1 / 2}$ (with

$\triangle \mathrm{BE} 9.8 \mathrm{eV}$ ). As reported previously [27], a decomposition and interpretation of $\mathrm{Cr} 2 \mathrm{p}$ core level spectra in the case of chromium (III) oxides is quite difficult due to presence of a multiplet splitting in the $2 p$ state of $\mathrm{Cr}$ (III) oxides $[28,29]$. The chromium (III) hydroxides, showed only one but broad peak as reported by Biesinger et al. [30]. The interpretation of $\mathrm{Cr}$ valence states is also hindered by the similar binding energies of $\mathrm{Cr}$ (III) components corresponding to hydroxides and fluorides and $\mathrm{Cr}(\mathrm{VI})$ components corresponding to oxides [21,31].

Due to the clear separation of $\mathrm{Cr} 2 \mathrm{p}_{3 / 2}$ and $\mathrm{Cr} 2 \mathrm{p}_{1 / 2}$ peaks, only a principal $\mathrm{Cr} 2 \mathrm{p}_{3 / 2}$ peak was decomposed here, as presented in Fig. $8 \mathrm{a}$. Three components can be distinguished: a principal symmetric peak at $577.4 \mathrm{eV}(\mathrm{FWHM}=2.1 \mathrm{eV})$, which is assigned to $\mathrm{Cr}(\mathrm{OH})_{3}$ and/or $\mathrm{CrOOH}$ $[32,33]$, and two lower intensity peaks at higher binding energies at

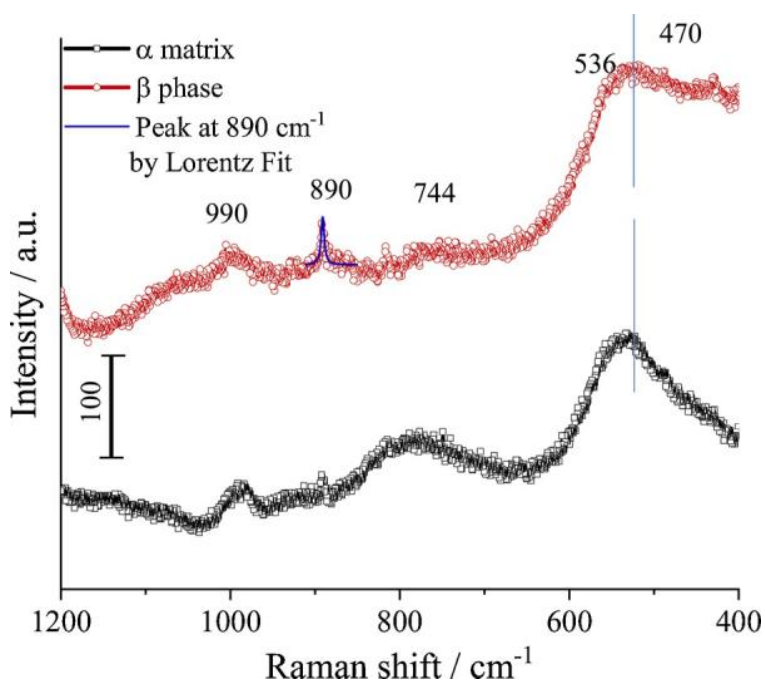

Fig. 9. Raman spectra of TCC-coated $\alpha$ matrix and $\beta$ phase in AZ91D alloy.

$578.6 \mathrm{eV}(\mathrm{FWHM}=1.6 \mathrm{eV})$ and at $580.1 \mathrm{eV}(\mathrm{FWHM}=2.1 \mathrm{eV})$ attributed to $\mathrm{Cr}_{2}\left(\mathrm{SO}_{4}\right)_{3}$ and $\mathrm{CrF}_{3}$, respectively. The binding energy of the principal peak is in good agreement with XPS data for $\mathrm{Cr}(\mathrm{OH})_{3}$ and $\mathrm{CrOOH}$ in the literature [28,29,34-36]. The chromium fluoride at a similar binding energy was also previously observed on converted AA2024 [18,21,37]. Similarly, to $\mathrm{CrF}_{3}$, the presence of $\mathrm{Cr}_{2}\left(\mathrm{SO}_{4}\right)_{3}$ was also detected on the conversion coating deposited on aluminium alloy [38]. The formation of a small quantity of $\mathrm{Cr}(\mathrm{VI})$ species cannot be completely ruled out, due to possible overlapping with a peak corresponding to $\mathrm{CrF}_{3}$. Depending on the reference, the binding energy of $\mathrm{Cr}(\mathrm{VI})$ species has been reported to be between 579.5 and $580.2 \mathrm{eV}$ and $\mathrm{Cr}$ (III) attributed to $\mathrm{CrF}_{3}$ between 579.3 and $580.8 \mathrm{eV}$ [32]. The presence of fluorides and sulphates can be confirmed by $\mathrm{F} 1 \mathrm{~s}$ (with a peak at around $685.9 \mathrm{eV}$ ) and S $2 \mathrm{p}$ (at around $168.8 \mathrm{eV}$ ) peaks, not shown here as high resolution spectra. A high intensity $F 1 \mathrm{~s}$ peak clearly observed on a survey spectrum (Fig. 5), cannot be explained only by the presence of a small quantity of $\mathrm{CrF}_{3}$. As already discussed above, low intensity peaks attributed to $\mathrm{AlF}_{3}$ and $\mathrm{MgF}_{2}$ were also detected. However, it can be inferred from the intensity of the $F 1 s$ peak that the highest binding energy $\mathrm{Cr} 2 \mathrm{p}$ peak at $580.1 \mathrm{eV}$ mostly originates from $\mathrm{Cr}(\mathrm{III})$ associated with $\mathrm{F}$ than $\mathrm{Cr}(\mathrm{VI})$ with $\mathrm{O}$. As explained above, the stoichiometric analysis of $\mathrm{Cr}(\mathrm{VI})-\mathrm{O}$ using $\mathrm{O} 1 \mathrm{~s}$ core level peak can be difficult due to overlapping of $\mathrm{Cr}(\mathrm{VI})-\mathrm{O}$ species and $\mathrm{C}-\mathrm{O}$ - or $\mathrm{Zr}-\mathrm{O}$ related species.

The $\mathrm{Zr} 3 \mathrm{~d}$ spectrum (Fig. 8) shows a $\mathrm{Zr} 3 \mathrm{~d}_{5 / 2}$ and $\mathrm{Zr} 3 \mathrm{~d}_{3 / 2}$ spin-orbit doublet at binding energies of 182.8 and $185.2 \mathrm{eV}$ (with $\mathrm{FWHM}=1.7 \mathrm{eV}$ 

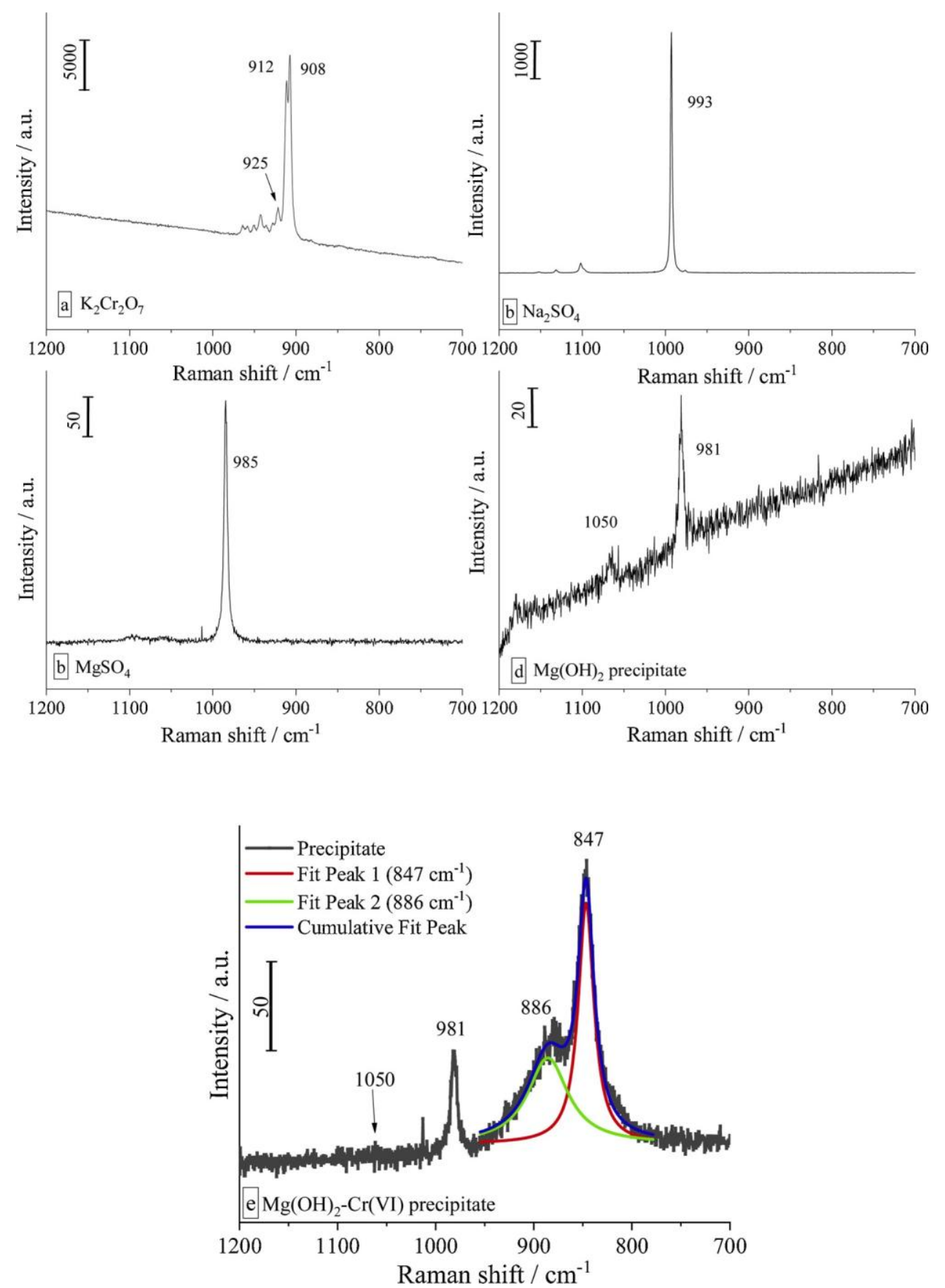

Fig. 10. Raman spectra for (a) $\mathrm{K}_{2} \mathrm{Cr}_{2} \mathrm{O}_{7}$, (b) $\mathrm{Na}_{2} \mathrm{SO}_{4}$, (c) $\mathrm{MgSO}_{4}$, (d) $\mathrm{Mg}(\mathrm{OH})_{2}$ and (e) $\mathrm{Mg}(\mathrm{OH})_{2}-\mathrm{Cr}(\mathrm{VI})$ precipitates.

for both peaks). The fitting of the $\mathrm{Zr}_{5 / 2}$ peak indicated the presence of $\mathrm{ZrO}_{2}$ at a binding energy in agreement with previous results [18,39]. No $\mathrm{ZrF}_{4}$ species were detected by XPS in the conversion coating. Table 3 reports the atomic percentages of chromium and zirconium ions (i.e. $\mathrm{Cr} /(\mathrm{Cr}+\mathrm{Zr}) \%$ and $\mathrm{Zr} /(\mathrm{Cr}+\mathrm{Zr}) \%)$ associated with $\left.\mathrm{Cr}(\mathrm{OH})_{3} / \mathrm{CrOOH}\right)$, $\mathrm{Cr}_{2}\left(\mathrm{SO}_{4}\right)_{3}, \mathrm{CrF}_{6}$ and $\mathrm{ZrO}_{2}$. The coating also contains lower amounts of other constituents, such as aluminium and magnesium species in the form of oxide, hydroxide or fluoride.

To further investigate the chemical composition of the TCC-coating on the AZ91D alloy Raman spectroscopy was employed. The spectrum (Fig. 9) show fingerprints of $\mathrm{ZrO}_{2}, \mathrm{MgF}_{2}$ and $\mathrm{SO}_{4}^{2-}$ ions at Raman shifts of 470,744 and $990 \mathrm{~cm}^{-1}$, respectively [19,40]. A broad peak at $\approx 530$ $\mathrm{cm}^{-1}$ is attributed to $\mathrm{Cr}(\mathrm{OH})_{3}$ and/or $\mathrm{Cr}_{2} \mathrm{O}_{3}$, which have Raman shifts at 526 and $536 \mathrm{~cm}^{-1}$, respectively [41]. Although $\mathrm{Cr}_{2} \mathrm{O}_{3}$ was not identified by XPS, it might exist at depths greater than the escape depth of the photoelectrons, or have been produced by dehydration of hydrated $\mathrm{Cr}$ (III) species under the laser irradiation.

A further peak at $890 \mathrm{~cm}^{-1}$ is assigned to $\mathrm{Cr}(\mathrm{VI})$ species. The peak was of higher intensity at the $\beta$ phase than the $\alpha$ matrix. In support of the assignment, Raman spectra were acquired for (i) $\mathrm{K}_{2} \mathrm{Cr}_{2} \mathrm{O}_{7}$ (Fig. 10 (a)), (ii) $\mathrm{Na}_{2} \mathrm{SO}_{4}$ (Fig. 10 (b)), $\mathrm{MgSO}_{4}$ (Fig. 10 (c)), (iii) $\mathrm{Mg}(\mathrm{OH})_{2}$ precipitate formed in $0.25 \mathrm{M} \mathrm{MgSO}_{4}$, with the $\mathrm{pH}$ adjusted to 10 by droplets of $\mathrm{NaOH}$ solution (Fig. 10 (d)) and $\mathrm{Mg}(\mathrm{OH})_{2}-\mathrm{Cr}(\mathrm{VI})$ precipitate formed in $0.25 \mathrm{M} \mathrm{K}_{2} \mathrm{Cr}_{2} \mathrm{O}_{7} / 0.5 \mathrm{M} \mathrm{MgSO}_{4}$ solution after adjustment to $\mathrm{pH} 10$ by droplets of $\mathrm{NaOH}$ solution. (Fig. 10 (e)). The precipitates in Figs. 10 (d, e) were filtered, rinsed in deionized water and dried. Peaks at 912, 908 $\mathrm{cm}^{-1}$ are assigned to $\mathrm{Cr}_{2} \mathrm{O}_{7}^{2-}$ (Fig. $10(\mathrm{a})$ ) and at 985 and $993 \mathrm{~cm}^{-1}$ to $\mathrm{SO}^{2-}$ (Fig. 10 (b, c) [41,42]. A peak due to sulphate residues is also evident for the precipitate. The $\mathrm{O}-\mathrm{H}$ band was observed at $1050 \mathrm{~cm}^{-1}$ with sulphate residues at $981 \mathrm{~cm}^{-1}$ in Fig. 10d [43]. The peak at 847 


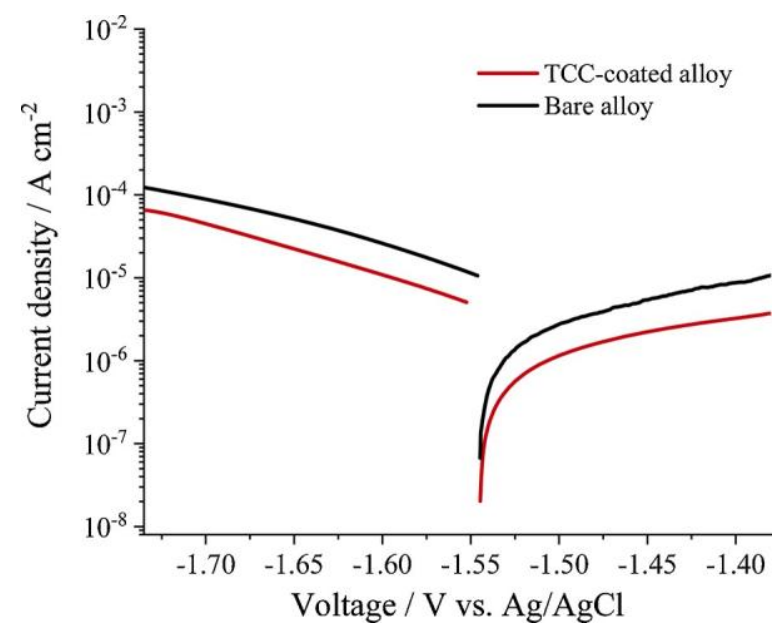

Fig. 11. Anodic and cathodic potentiodynamic polarization curves for the pretreated (bare) and TCC-coated AZ91D alloy specimens in $0.05 \mathrm{M}$ $\mathrm{Na}_{2} \mathrm{SO}_{4}$ solution.

(a)

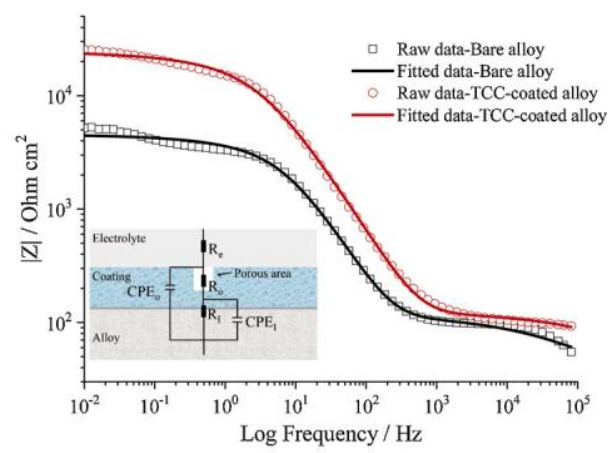

(b)

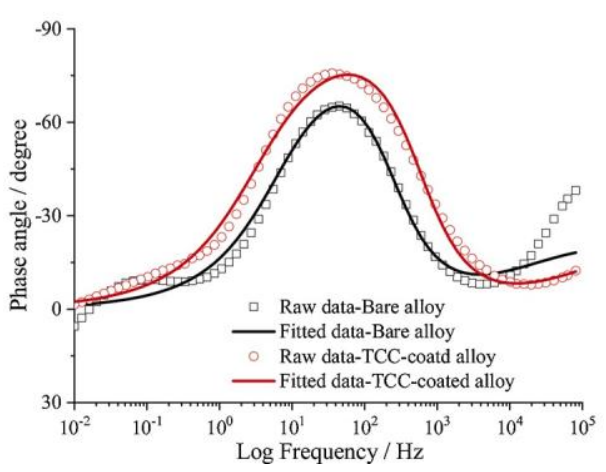

Fig. 12. EIS for pretreated bare AZ91D alloy ( $\square$ ) and TCC-coated AZ91D alloy (o) specimens in $0.05 \mathrm{M} \mathrm{Na}_{2} \mathrm{SO}_{4}$ solution: (a) $|\mathrm{Z}|$-frequency and (b) phase anglefrequency.

$\mathrm{cm}^{-1}$ for $\mathrm{Mg}(\mathrm{OH})_{2}-\mathrm{Cr}(\mathrm{VI})$ is in agreement the reported value for $\mathrm{CrO}_{4}^{2-}$ species [40]. The peak at $886 \mathrm{~cm}^{-1}$ peak is assigned to $\mathrm{Cr}_{2} \mathrm{O}^{2-}$ and/or $\mathrm{HCrO}_{4}$ - species, with the shift influenced by the presence of $\mathrm{Mg}(\mathrm{II})$ and possibly $\mathrm{Na}(\mathrm{I})$ species. $\mathrm{HCrO}_{4}$ - have been previously assigned a Raman shift of $899 \mathrm{~cm}^{-1}$ [44]. Using mixed oxides containing $\mathrm{Cr}$ (VI) and $\mathrm{Cr}$ (III) or $\mathrm{Al}(\mathrm{III})$, others have shown that the Raman shift depends on the $\mathrm{Cr}(\mathrm{VI})$ environment $[41,45]$.
Table 4

Fitted electrochemical impedance spectroscopy parameters obtained for pretreated bare and TCC-coated AZ91D alloy.

\begin{tabular}{|c|c|c|}
\hline & Bare alloy & TCC-coated alloy \\
\hline $\mathrm{R}_{\mathrm{e}}\left(\Omega \mathrm{cm}^{2}\right)$ & $18 \pm 2$ & $18 \pm 1$ \\
\hline $\mathrm{CPE}_{\circ}\left(\mu \mathrm{Ss}^{-2} \mathrm{~cm}^{-2}\right)$ & $27 \pm 5.3$ & $4.3 \pm 1.8$ \\
\hline$R_{0}\left(\Omega \mathrm{cm}^{2}\right)$ & $100 \pm 11$ & $106 \pm 12$ \\
\hline $\mathrm{CPE}_{\mathrm{I}}\left(\mu \mathrm{Ss}^{-2} \mathrm{~cm}^{-2}\right)$ & $5.7 \pm 1.3$ & $2.2 \pm 0.9$ \\
\hline$R_{1}\left(\Omega \mathrm{cm}^{2}\right)$ & $4436 \pm 121$ & $24,359 \pm 150$ \\
\hline
\end{tabular}

\subsection{Electrochemical characterization}

In order to demonstrate the barrier properties of the TCC coating deposited on the pre-treated AZ91D alloy, potentiodynamicpolarization and electrochemical impedance spectroscopy were performed in $0.05 \mathrm{M}$ $\mathrm{Na}_{2} \mathrm{SO}_{4}$ solution. Cathodic and anodic polarization curves (Fig. 11) reveal the reduced current density by a factor of 2 relative to that of the uncoated specimen. The curves showed no well-defined Tafel regions to determine the corrosion current density at the corrosion potential.

Fig. $12(\mathrm{a}, \mathrm{b})$ displays typical examples of Bode plots of EIS datafor uncoated and TCC-coated specimens. The data were fitted with an equivalent circuit (inset in Fig. 12) that represents a barrier coating comprising an outer $\mathrm{ZrO}_{2} / \mathrm{Cr}(\mathrm{OH})_{3} / \mathrm{CrOOH}$ layer and an inner Mg-F-O layer, the latter reported by Brady et al. [15]. The components of the equivalent circuit are $R_{e}$ the electrolyte resistance, $R_{\circ}$ and $R_{l}$ - the resistances of the outer and inner layers, and $\mathrm{CPE}_{O}$ and $\mathrm{CPE}_{\mid}$are constant phase elements for the respective layers. Since a film consisting of an outer hydroxide layer and inner oxide layer has been reported to form in $\mathrm{Na}_{2} \mathrm{SO}_{4}$ solution [46], a similar equivalent circuit was employed to the pretreated specimens. CPEs replaced capacitances due to the non-ideal behavior of the layers on both uncoated and coated specimens. The average and standard deviations of each circuit element derived from fitting of the data in triplicated tests are listed in Table 4.

The outer layers of the pre-treated and TCC-coated AZ91D alloy specimens show similar resistances of $100 \Omega \mathrm{cm}^{2}$. In contrast, the resistances of the inner layers of the respective specimens were significantly higher, namely $4.41 \AA^{3}$ and $2.410^{4} \mathrm{R} \mathrm{cm}^{2}$. Thus, the inner Mg-FO layer of the TCC coat provided the main protection, with a resistance about 5 times that of the uncoated specimen. The higher CPEs of the inner and outer layers of the TCC-coated specimen suggest greater layer thicknesses compared with those of the uncoated alloy. The low resistance of the outer layer may be caused by defects in the coating, such as cracks or cavities, or easy transport of species through the coating, for instance due to a gel-like structure. In practice, it is expected that the TCC coating would be applied beneath an organic coating in part of a protection scheme that would provide corrosion resistance in more aggressive environments, for instance when chloride ions are present.

\section{Conclusions}

TCC coating of AZ91B alloy results in deposition of coating material above both the $\alpha$ matrix and the $\beta$ phase. A thicker layer is produced at the cathodic grain boundary $\beta$ phase compared with the $\alpha$ matrix owing to a greater $\mathrm{pH}$ rise at the former location that results from reduction of oxygen and $\mathrm{H}^{+}$ions.

The atomic ratio of chromium to zirconium in the coating was approximately 8.5. $\mathrm{Cr}(\mathrm{OH})_{3} / \mathrm{CrOOH}, \mathrm{Cr}_{2}\left(\mathrm{SO}_{4}\right)_{3}, \mathrm{CrF}_{3}$ and $\mathrm{ZrO}_{2}$ species were main components of the deposited coating material. $\mathrm{Cr}(\mathrm{VI})$ was also present, particularly in the coating above cathodic $\beta$ phase. The $\mathrm{Cr}(\mathrm{VI})$ was generated by oxidation of $\mathrm{Cr}(\mathrm{III})$ by $\mathrm{H}_{2} \mathrm{O}_{2}$ produced by reduction of oxygen

Electrochemical impedance spectroscopy and potentiodynamic polarization revealed that the TCC coating provided a barrier to corrosion of the alloy. The protection was mainly due to an inner Mg-rich layer 
layer of the coating located beneath the less protective deposited layer.

\section{Author statement}

Jiantao Qi carried out the data curation and writing-Original draft preparation;

Zonghao Ye carried out the sample preparation and microstructure investigation;

Ning Gong carried out the Raman sample preparation and investigation;

Xuelian Qu carried out the electrochemical measurement;

Dimitri Mercierc provided the electrochemical methodology and

validation;

Jolanta Światowskac carried out the XPS data analyses and paper reviewing and editing;

Peter Skeldond carried out the paper writing-reviewing and editing; Philippe Marcusc provided the paper writing-reviewing and editing;

\section{Declaration of Competing Interest}

The authors declare that they have no known competing financial interests or personal relationships that could have appeared to influence the work reported in this paper.

\section{Acknowledgements}

The following are acknowledged for support: National Natural Science Foundation of China (51701239), Fundamental Research Funds for the Central Universities (18CX02128A) and Graduate Innovation Project from China University of Petroleum (East China) (YCX2020093). The authors also wish to thank Dr. Changrun Cai, of Nanoport, Thermo Fisher Scientific (Shanghai, China) for assistance with SEM.

\section{References}

[1] A. Kiełbus, R. Jarosz, A. Gryc, Effect of modification on microstructure and properties of AZ91 magnesium alloy, Crystals 10 (2020) 536.

[2] A. Zarebidaki, H. Mahmoudikohani, M.-R. Aboutalebi, Microstructure and corrosion behavior of electrodeposited nano-crystalline nickel coating on AZ91 Mg alloy, J. Alloys. Compd. 615 (2014) 825-830.

[3] L. Yang, X. Zhou, M. Curioni, S. Pawar, H. Liu, Z. Fan, G. Scamans, G. Thompson, Corrosion behavior of pure magnesium with low iron content in $3.5 \mathrm{wt} \% \mathrm{NaCl}$ solution, J. Electrochem. Soc. 162 (2015) C362-C368.

[4] H. Huo, Y. Li, F. Wang, Corrosion of AZ91D magnesium alloy with a chemical conversion coating and electroless nickel layer, Corros. Sci. 46 (2004) 1467-1477.

[5] G. Duan, L. Yang, S. Liao, C. Zhang, X. Lu, Y. Yang, B. Zhang, Y. Wei, T. Zhang, B. Yu, X. Zhang, F. Wang, Designing for the chemical conversion coating with high corrosion resistance and low electrical contact resistance on AZ91D magnesium alloy, Corros. Sci. 135 (2018) 197-206.

[6] W. Zai, Y. Su, H.C. Man, J. Lian, G. Li, Effect of $\mathrm{pH}$ value and preparation temperature on the formation of magnesium phosphate conversion coatings on AZ31 magnesium alloy, Appl. Surf. Sci. 492 (2019) 314-327.

[7] Z. Chunyan, L. Shangju, Y. Baoxing, L. Xiaopeng, C. Xiao-Bo, Z. Tao, W. Fuhui, Ratio of total acidity to $\mathrm{pH}$ value of coating bath: a new strategy towards phosphate conversion coatings with optimized corrosion resistance for magnesium alloys, Corros. Sci. 150 (2019) 279-295.

[8] S. Gheytani, Y. Liang, Y. Jing, J.Q. Xu, Y. Yao, Chromate conversion coated aluminium as a light-weight and corrosion-resistant current collector for aqueous lithium-ion batteries, J. Mater. Chem. A Mater. Energy Sustain. 4 (2016) 395-399.

[9] Y. Liu, P. Skeldon, G.E. Thompson, H. Habazaki, K. Shimizu, Chromate conversion coatings on aluminium-copper alloys, Corros. Sci. 47 (2005) 341-354.

[10] M.W. Kendig, R.G. Buchheit, Corrosion inhibition of aluminum and aluminum alloys by soluble chromates, chromate coatings, and chromate-free coatings, Corrosion 59 (2003) 379-400.

[11] D.B. Mitton, A. Carangelo, A. Acquesta, T. Monetta, M. Curioni, F. Bellucci, Selected $\mathrm{Cr}(\mathrm{VI})$ replacement options for aluminum alloys: a literature survey, Corro. Rev. 35 (2017) 365-381.

[12] B. Mingo, Y. Guo, A. Němcová, A. Gholinia, M. Mohedano, M. Sun, A. Matthews, A. Yerokhin, Incorporation of halloysite nanotubes into forsterite surface layer during plasma electrolytic oxidation of AM50 Mg alloy, Electrochim. Acta 299 (2019) 772-788.

[13] Z. Chen, H. Ji, X. Geng, X. Chen, X. Yong, S. Zhang, 3-D distribution characteristics of the micro-defects in the PEO coating on ZM6 mg-alloy during corrosion, Corros. Sci. 174 (2020), 108821.
H.-Y. Hsiao, W.-T. Tsai, Characterization of anodic films formed on AZ91D magnesium alloy, Surf. Coat. Technol. 190 (2005) 299-308.

[15] M.P. Brady, D.N. Leonard, H.M. Meyer lii, J.K. Thomson, K.A. Unocic, H. H. Elsentriecy, G.L. Song, K. Kitchen, B. Davis, Advanced characterization study of commercial conversion and electrocoating structures on magnesium alloys AZ31B and ZE10A, Sur. Coat. Technol, 294 (2016) 164-176.

[16] G. Song, A. Atrens, X. Wu, B. Zhang, Corrosion behaviour of AZ21, AZ501 and AZ91 in sodium chloride, Corros. Sci. 40 (1998) 1769-1791.

[17] X. Verdalet-Guardiola, B. Fori, J.-P. Bonino, S. Duluard, C. Blanc, Nucleation and growth mechanisms of trivalent chromium conversion coatings on 2024-T3 aluminium alloy, Corros. Sci. 155 (2019) 109-120.

[18] R. Viroulaud, J. Światowska, A. Seyeux, S. Zanna, J. Tardelli, P. Marcus, Influence of surface pretreatments on the quality of trivalent chromium process coatings on aluminum alloy, Appl. Surf. Sci. 423 (2017) 927-938.

[19] J.T. Qi, T. Hashimoto, J.R. Walton, X. Zhou, P. Skeldon, G.E. Thompson, Trivalent chromium conversion coating formation on aluminium, Surf. Coat. Technol. 280 (2015) 317-329.

[20] L. Li, A.L. Desouza, G.M. Swain, In situ pH measurement during the formation of conversion coatings on an aluminum alloy (AA2024), Analyst 138 (2013) 4398-4402.

[21] J. Qi, T. Hashimoto, J. Walton, X. Zhou, P. Skeldon, G.E. Thompson, Formation of a trivalent chromium conversion coating on AA2024-T351 alloy, J. Electrochem. Soc. 163 (2016) C25-C35.

[22] K. Domen, T.J. Chuang, Laser induced photodissociation and desorption. I. $\mathrm{CH}_{2} \mathrm{I}_{2}$ adsorbed on $\mathrm{Al}_{2} \mathrm{O}_{3}$, J. Chem. Phys. 90 (1989) 3318.

[23] I. Olefjord, H.J. Mathieu, P. Marcus, Intercomparison of surface analysis of thin aluminium oxide films, Surf. Interface Anal. 15 (1990) 681-692.

[24] S.C. Stuart, E. Satchet, A. Sandin, J.P. Maria, J.E. Rowe, D.B. Dougherty, M. Ulrich, Smooth $\mathrm{MgO}$ films grown on graphite and graphene by pulsed laser deposition, J. Vac. Sci. Technol. B 31 (2013), 051804.

[25] L. Savio, E. Celasco, L. Vattuone, M. Rocca, Enhanced reactivity at metal oxide interface: water interaction with MgO ultrathin films, J. Phys. Chem. B 108 (2004) $7771-7778$.

[26] R.G. Haverkamp, J.B. Metson, M.M. Hyland, B.J. Welch, Adsorption of hydrogen fluoride on alumina, Surf. Interface Anal. 19 (1992) 139-144.

[27] M. Ely, J. Światowska, A. Seyeux, S. Zanna, P. Marcus, Role of post-treatment in improved corrosion behavior of trivalent chromium protection (TCP) coating deposited on aluminum alloy 2024-T3, J. Electrochem. Soc. 164 (2017) C276-C284.

[28] A.R. Pratt, N.S. Mclntyre, Comment on 'Curve fitting of $\mathrm{Cr} 2 \mathrm{p}$ photoelectron spectra of $\mathrm{Cr}_{2} \mathrm{O}_{3}$ and $\mathrm{CrF}_{3}$ '. Surf. Interface Anal. 24 (1996) 529-530.

[29] M. Aronniemi, J. Sainio, J. Lahtinen, Chemical state quantification of iron and chromium oxides using XPS: the effect of the background subtraction method, Surf. Sci. 578 (2005) 108-123.

[30] M.C. Biesinger, B.P. Payne, A.P. Grosvenor, L.W.M. Lau, A.R. Gerson, R.S.C. Smart, Resolving surface chemical states in XPS analysis of first row transition metals, oxides and hydroxides: Cr, Mn, Fe, Co and Ni, Appl. Surf. Sci. 257 (2011) 2717-2730.

[31] C.D. Wagner, W.M. Riggs, L.E. Davis, J.F. Moulder, G.E. Muilenberg, Handbook of X-ray Photoelectron Spectroscopy. Perkin-elmer Corporation, Physical electronics division, USA, 1978

[32] Q. Liu, H. Liu, H. Chen, X. Wang, D. Hu, X. Cheng, H. Xu, Thermodynamic investigation with chemical kinetic analysis on the reoxidation phenomenon of the Cr(iii) in air, RSC Adv. 10 (2020) 27775-27787.

[33] A.R. Brooks, C.R. Clayton, K. Doss, Y.C. Lu, On the role of $\mathrm{Cr}$ in the passivity of stainless steel, J. Electrochem. Soc. 133 (1986) 2459-2464.

[34] A.E. Hughes, R.J. Taylor, B.R.W. Hinton, Chromate conversion coatings on $2024 \mathrm{Al}$ alloy, Surf. Interface Anal. 25 (1997) 223-234.

[35] B. Stypula, J. Stoch, The characterization of passive films on chromium electrodes by XPS, Corros. Sci. 36 (1994) 2159-2167.

[36] W.P. Yang, D. Costa, P. Marcus, Resistance to pitting and chemical composition of passive films of a $\mathrm{Fe}-17 \% \mathrm{Cr}$ alloy in chloride-containing acid solution, J. Electrochem. Soc. 141 (1994) 2669.

[37] T. Gross, D. Treu, E. Ünveren, E. Kemnitz, W.E.S. Unger, Characterization of Cr(III) compounds of O, OH, F and Cl by XPS, Surf. Sci. Spectra. 15 (2008) 77-123.

[38] P. Campestrini, G. Goeminne, H. Terryn, J. Vereecken, J.H.W. de Wit, Chromate conversion coating on aluminum alloys - I. Formation mechanism, J. Electrochem. Soc. 151 (2004) B59-B70.

[39] S. Sinha, S. Badrinarayanan, A.P.B. Sinha, Interaction of oxygen with $\mathrm{Zr}_{76} \mathrm{Fe}_{24}$ metglass: an X-ray photoelectron spectroscopy study, J. Less-Common Met. 125 (1986) 85-95.

[40] M.L. Lesiecki, J.W. Nibler, Infrared and Raman spectra and structures of matrix isolated magnesium dihalides: MgF2, MgCl2, MgBr2, and Mgl2, J. Chem. Phys. 64 (1976) 871-884.

[41] L.L. Li, D.Y. Kim, G.M. Swain, Transient formation of chromate in trivalent chromium process (TCP) coatings on AA2024 as probed by Raman spectroscopy, J. Electrochem. Soc. 159 (2012) C326-C333.

[42] J. Qi, J. Walton, G.E. Thompson, S.P. Albu, J. Carr, Spectroscopic studies of chromium VI formed in the trivalent chromium conversion coatings on aluminum, J. Electrochem. Soc. 163 (2016) C357-C363.

[43] A. Maltseva, S.V. Lamaka, K.A. Yasakau, D. Mei, D. Kurchavov, M.L. Zheludkevich, G. Lefèvre, P. Volovitch, In situ surface film evolution during Mg aqueous corrosion in presence of selected carboxylates, Corros. Sci. (2020) 108484. In Press. 
[44] J.D. Ramsey, R.L. McCreery, In situ Raman microscopy of chromate effects on corrosion pits in aluminum alloy, J. Electrochem. Soc. 146 (1999) 4076-4081.

[45] L. Xia, R.L. McCreery, Chemistry of a chromate conversion coating on aluminum alloy AA2024-T3 probed by vibrational spectroscopy, J. Electrochem. Soc. 145 1998) 3083-3089.
[46] A. Abildina, A. Argimbayeva, A. Kurbatov, Y. Bakhytzhan, G. Rakhymbay, M. Wark, P. Bottke, Study of polarization characteristics of corrosion films on magnesium in sulfate-containing electrolytes, Appl. Sci. Basel (Basel) 10 (2020) $1406-1422$. 